\title{
ARTICLE
}

\section{Intravenous immune globulin suppresses angiogenesis in mice and humans}

Reo Yasuma ${ }^{1,2,17}$, Valeria Cicatiello ${ }^{3,4,17}$, Takeshi Mizutani ${ }^{1,17}$, Laura Tudisco ${ }^{3,17}$, Younghee Kim ${ }^{1,17}$, Valeria Tarallo ${ }^{1,3}$, Sasha Bogdanovich ${ }^{1}$, Yoshio Hirano ${ }^{1}$, Nagaraj Kerur ${ }^{1}$, Shengjian $\mathrm{Li}^{1}$, Tetsuhiro Yasuma ${ }^{1}$, Benjamin J Fowler ${ }^{1,5}$, Charles B Wright ${ }^{1}$, Ivana Apicella ${ }^{3}$, Adelaide Greco ${ }^{6,7}$, Arturo Brunetti ${ }^{6,7}$, Balamurali K Ambati ${ }^{8,9}$, Sevim Barbasso Helmers ${ }^{10}$, Ingrid E Lundberg ${ }^{10}$, Ondrej Viklicky ${ }^{11}$, Jeanette HW Leusen ${ }^{12}$, J Sjef Verbeek ${ }^{13}$, Bradley D Gelfand ${ }^{1,14,15}$, Ana Bastos-Carvalho ${ }^{1}$, Sandro De Falco ${ }^{3,16,17}$ and Jayakrishna Ambati ${ }^{1,5,17}$

Human intravenous immune globulin (IVlg), a purified lgG fraction composed of $\sim 60 \%$ lgG1 and obtained from the pooled plasma of thousands of donors, is clinically used for a wide range of diseases. The biological actions of IVlg are incompletely understood and have been attributed both to the polyclonal antibodies therein and also to their $\lg (\mathrm{lgG})$ Fc regions. Recently, we demonstrated that multiple therapeutic human lgG1 antibodies suppress angiogenesis in a target-independent manner via FcyRl, a high-affinity receptor for IgG1. Here we show that IVIg possesses similar anti-angiogenic activity and inhibited blood vessel growth in five different mouse models of prevalent human diseases, namely, neovascular age-related macular degeneration, corneal neovascularization, colorectal cancer, fibrosarcoma and peripheral arterial ischemic disease. Angioinhibition was mediated by the Fc region of IVIg, required FcyRI and had similar potency in transgenic mice expressing human FcyRs. Finally, IVIg therapy administered to humans for the treatment of inflammatory or autoimmune diseases reduced kidney and muscle blood vessel densities. These data place IVlg, an agent approved by the US Food and Drug Administration, as a novel angioinhibitory drug in doses that are currently administered in the clinical setting. In addition, they raise the possibility of an unintended effect of IVlg on blood vessels.

Signal Transduction and Targeted Therapy (2016) 1, 15002; doi:10.1038/sigtrans.2015.2; published online 28 January 2016

\section{INTRODUCTION}

Human intravenous immune globulin (IVIg) is a biological product obtained by pooling polyclonal IgG from thousands of healthy donors. It is approved for the treatment of numerous primary immunodeficiencies. ' It is also widely used in an 'off-label' manner to treat a wide range of dermatological, neurological, inflammatory and transplantation-related diseases. The biological actions of IVlg have been attributed both to the polyclonal specificities of the antibodies therein ${ }^{2}$ and to immunomodulatory or anti-inflammatory effects driven by their IgG Fc regions. ${ }^{3,4}$ In a companion paper, we demonstrate that therapeutic human IgG1 antibodies can suppress angiogenesis in a target-independent manner via FcyRl, ${ }^{5}$ a high-affinity receptor for $\operatorname{lgG} 1 .^{6-8}$ Therefore, we tested whether IVIg, which is composed of $\sim 60 \% \operatorname{lgG} 1$, also possessed similar anti-angiogenic properties.

\section{MATERIALS AND METHODS}

Animals

All animal experiments were in accordance with the guidelines of the relevant institutional authorities. Male mice, aged 4-8 weeks, were randomized 1:1 to treatment with active drug versus inactive drug or control treatments.

\begin{abstract}
Drug injections
For systemic administration in corneal, choroid and hind limb angiogenesis experiments, human IVlg (0.017-2 g/kg/dose; Gammagard, Baxter (Deerfield, IL, USA) or Privigen, CSL Behring (King of Prussia, PA, USA)) or PBS was injected into the tail vein immediately after injury and 3 days later. In tumor experiments, IVlg was injected twice a week. For intravitreous administration in choroidal angiogenesis experiments, human IVIg $(40 \mu \mathrm{g}, 1 \mu \mathrm{l})$ or PBS was administered into the vitreous humor of mice using a 33-gauge double-caliber needle (Ito Corporation, Fuji, Japan) once, immediately after laser injury, as previously described. ${ }^{9}$ FCGRIA or LuC small interfering RNAs $(2 \mu \mathrm{g}, 1 \mu \mathrm{l})$ was administered into the vitreous 1 day before intravitreous human IVIg administration and laser treatment.
\end{abstract}

\section{Corneal angiogenesis}

Nylon sutures (Mani, Utsunomiya, Japan) were placed into the corneal stroma of mice, and on day 10 after injury, we calculated the mean percentage $\mathrm{CD} 31^{+} \mathrm{Lyve} 1^{-}$blood vessel areas for corneal flat mounts with ImageJ (US National Institutes of Health, Bethesda, MD, USA) as previously reported. ${ }^{10,11}$

\footnotetext{
'Department of Ophthalmology and Visual Sciences, University of Kentucky, Lexington, KY, USA; ${ }^{2}$ Department of Ophthalmology, Nagoya University Graduate School of Medicine, Nagoya, Japan; ${ }^{3}$ Angiogenesis Lab, Institute of Genetics and Biophysics-CNR, Naples, Italy; ${ }^{4}$ Bio-Ker, MultiMedica Group, Naples, Italy; ${ }^{5}$ Department of Physiology, University of Kentucky, Lexington, KY, USA; ${ }^{6}$ Department of Advanced Biomedical Sciences, University of Naples 'Federico II', Naples, Italy; ${ }^{7} \mathrm{CEINGE}$-Biotecnologie Avanzate, s.C. ar.I., Naples, Italy; ${ }^{8}$ Department of Ophthalmology and Visual Sciences, Moran Eye Center, University of Utah School of Medicine, Salt Lake City, UT, USA; ${ }^{9}$ Department of Ophthalmology, Veterans Affairs Salt Lake City Healthcare System, Salt Lake City, UT, USA; ${ }^{10}$ Rheumatology Unit, Department of Medicine, Karolinska Institutet, Karolinska University Hospital, Stockholm, Sweden; ${ }^{11}$ Department of Nephrology, Institute for Clinical and Experimental Medicine, Prague 4, Czech Republic; ${ }^{12} \mathrm{Immunotherapy} \mathrm{Laboratory,}$ Laboratory for Translational Immunology, University Medical Center Utrecht, Utrecht, The Netherlands; ${ }^{13}$ Department of Human Genetics, Leiden University Medical Center, Leiden, The Netherlands; ${ }^{14}$ Department of Biomedical Engineering, University of Kentucky, Lexington, KY, USA; ${ }^{15}$ Department of Microbiology, Immunology, and Molecular Genetics, University of Kentucky, Lexington, KY, USA and ${ }^{16}$ IRCCS MultiMedica, Milano, Italy.

Correspondence: S De Falco (jamba2@email.uky.edu) or J Ambati (sandro.defalco@igb.cnr.it)

${ }^{17}$ These authors contributed equally to this work.

Received 29 August 2015; revised 25 November 2015; accepted 25 November 2015
} 


\section{Choroidal angiogenesis}

Laser photocoagulation (OcuLight GL, IRIDEX, Mountain View, CA, USA) was performed on both eyes of mice to induce neovascularization, and on day 7 after injury, choroidal angiogenesis volumes were measured by scanning laser confocal microscopy (TCS SP5, Leica, Wetzlar, Germany) as previously reported with $0.7 \%$ fluorescein isothiocyanate-conjugated Isolectin B4 (Vector Laboratories, Burlingame, CA, USA). ${ }^{12}$

\section{Hind limb ischemia angiogenesis}

Unilateral proximal femoral artery ligation was performed as previously described, ${ }^{13}$ and on day 7 after surgery, both anterior and posterior muscles from ischemic and non-ischemic hind limbs were harvested and processed for immunohistochemical analysis for vessel quantification. Color laser Doppler analysis was also performed using a dedicated Laser Doppler Perfusion Imaging System (PeriScan PIM II System, Perimed AB, Järfälla, Sweden).

\section{Tumor experiments}

HCT-116 colon carcinoma cells for xenograft tumors and T241 fibrosarcoma cells for syngenic tumors were injected s.c. into the right flank of CD1 nude athymic mice or $\mathrm{C} 57 \mathrm{BI} / 6 \mathrm{~J}$ and $\mathrm{Fcgr}^{-1-}$ mice, respectively. Tumor growth was monitored by measuring the shortest $(d)$ and the longest $(D)$ diameters using a caliper. The volume (TV) was calculated according to the formula: TV $\left(\mathrm{mm}^{3}\right)=d^{2} \times D / 2$.

\section{Statistical analyses}

Choroidal angiogenesis volumes per laser lesion were compared by hierarchical logistic regression using repeated measures analysis as previously described. ${ }^{14}$ Differences in pre- and post-treatment blood vessel densities in human tissue biopsies were compared by two-tailed paired Student $t$-test, with mean and 95\% confidence interval values reported. For other comparisons, we used the Mann-Whitney U-test with Bonferroni correction for statistical comparison of multiple variables. Results are expressed as mean \pm s.e.m. Type-I error not exceeding 0.05 was deemed significant.

\section{RESULTS}

We tested the effect of IVIg in the following five different mouse models of angiogenesis: laser-induced choroidal angiogenesis, a model of neovascular age-related macular degeneration $(\mathrm{AMD}){ }^{15,16}$ suture-induced corneal angiogenesis, ${ }^{10,11}$ hind limb ischemia induced by femoral artery ligation ${ }^{11,13}$ and a syngeneic mouse fibrosarcoma tumor model, ${ }^{17}$ all in wild-type mice, as well as a human xenograft model of colorectal carcinoma in nude mice. ${ }^{18}$ IVlg inhibited angiogenesis in all five models (Figures 1a-g). In addition, and consistent with the concept that reduction of tumor vascularization induces tumor growth inhibition, ${ }^{19-21}$ tumor volume was reduced in IVlg-treated mice in both tumor models (Figures $1 \mathrm{~h}$ and i). Furthermore, IVIg reduced muscle vascular reperfusion as measured by laser Doppler imaging (Figures $1 \mathrm{j}$ and $\mathrm{k}$ ). IVlg also reduced infiltration of $\mathrm{F} 4 / 80+$ macrophages, which have a key role in multiple models of angiogenesis, into the ischemic hind limb of wild-type mice (Supplementary Figure 1).

High-dose IVlg ( $2 \mathrm{~g} / \mathrm{kg}$ of body weight) is commonly administered for the treatment of autoimmune or inflammatory diseases. ${ }^{3}$ We confirmed that the anti-angiogenic effect of IVlg was dose-dependent and occurred with clinically relevant doses $(0.017-2 \mathrm{~g} / \mathrm{kg}$ of body weight) in wild-type mice in both the colorectal cancer and choroidal angiogenesis models (Figures 1e, g and I). Similarly, the observed reduction in tumor volume was also dose-dependent (Figure 1i).

Because local therapy in the form of intraocular injections is widely used in ophthalmic disorders, we next sought to determine whether IVIg also inhibited angiogenesis when delivered locally. We tested the effect of IVIg on choroidal angiogenesis when administered by intravitreous injection. IVlg delivered by this local route decreased angiogenesis as effectively as by IV administration (Figure 1m; compare with Figure 1a).

IVIg contains thousands of polyvalent antibodies, and it is possible that the Fab regions of some of them could target angiogenic molecules. Indeed, certain anti-inflammatory actions of IVIg have been attributed to the presence of specific antigentargeting antibodies. ${ }^{2}$ To test which region of IVIg was responsible for its angioinhibitory effect, we treated mice with papain-derived Fc (IVIg-Fc) or Fab (IVlg-Fab) fragments of IVlg (Supplementary Figure 2). Consistent with the idea that lgG-mediated angioinhibition is not because of the specific antigen-antibody targeting of angiogenic molecules, ${ }^{5}$ systemic administration of IVlg-Fc inhibited choroidal and tumor angiogenesis in wild-type mice, whereas administration of IVIg-Fab by the same route did not do so (Figures $2 \mathrm{a}$ and $\mathrm{b}$ ). As we had observed previously with full-length IVlg-Fc also inhibited xenograft tumor growth, whereas IVlg-Fab had no effect (Figure 2c).

IVIg has been reported to suppress inflammation in mice both via activating ${ }^{22}$ and inhibitory ${ }^{23}$ receptors for the Fc region of lgGs, the FcyRs. We recently showed that multiple human IgG1 antibodies and their Fc fragments suppressed angiogenesis via the activating FcyRl, and this anti-angiogenic effect was abolished in mice deficient in this receptor. ${ }^{5}$ Consistent with those findings, IVlg did not suppress angiogenesis in $\mathrm{Fcgr}^{-/-}$mice, which do not express FcyRl (Figures 2d and e), or in Fcer1g ${ }^{-/-}$mice, which do not express the $\gamma$-chain of Fc receptors, therefore lacking signaling for all activating FcyRs (Figure 2g). In contrast, IVlg did suppress angiogenesis in $\mathrm{Fcgr2b^{-l- }}$ mice, which do not express the inhibitory FcyRII (Supplementary Figure 3). Tumor growth was also not abrogated by IVIg in $\mathrm{Fcgrl}^{-1-}$ mice (Figure 2f). Furthermore, and consistent with the hypothesis that IVIg inhibits blood vessel growth via interaction of its Fc fragments with FcyRl, papain-cleaved IVIg-Fc also did not reduce angiogenesis in $\mathrm{Fcgr1}^{-1-}$ mice (Figure 2h).

Figure 1. IVlg inhibited angiogenesis in five mouse models. (a) IVlg decreased choroidal angiogenesis, corneal angiogenesis and ischemic hind limb angiogenesis in wild-type mice. Choroidal angiogenesis volume was measured 7 days after laser injury and normalized to PBS treatment (IV PBS); $n=8$. Corneal area of angiogenesis was measured 10 days after suture injury and normalized to PBS group; $n=16$. Quantification of muscle CD31 immunolocalization was done 7 days after injury; $n=7$. (b) Representative photos of corneal flat mounts showing reduced growth of blood vessels (CD31+, red) in eyes treated with IVlg, but not in eyes treated with IV PBS. Scale bar, $500 \mu \mathrm{m}$. (c) Representative choroidal angiogenesis lesions (endothelial cells stained in green) show reduced choroidal angiogenesis in mice treated with IVlg but not in mice treated with IV PBS. Scale bar, $50 \mu \mathrm{m}$. (d) Representative images of muscle CD31 immunolocalization in the different treatment groups of the hind limb ischemia model. Scale bar, $100 \mu \mathrm{m}$. (e-g) IVlg decreased syngeneic tumor angiogenesis in wild-type mice and xenograft tumor angiogenesis in nude mice, as seen in (e) quantification of tumor CD31 immunolocalization ( $n=7)$, and representative histology images of syngenic (f) and xenograft (g) tumor tissue (CD31+, brown). The angioinhibitory effect was dose-dependent in the xenograft tumor model. IVlg doses ranged from 0.5 to $2 \mathrm{~g} / \mathrm{kg}$, delivered twice weekly. Scale bar, $100 \mu \mathrm{m}$. (h, i) IVlg reduced tumor growth in the syngeneic model (h) and in the xenograft model (i). In the xenograft model, the reduction in tumor volume was dose-dependent. IVlg doses ranged from 0.5 to $2 \mathrm{~g} / \mathrm{kg}$, delivered twice weekly; $n=7$. (j, k) Treatment of ischemic hind limb with IVlg in wild-type mice suppressed muscle revascularization and decreased blood vessel perfusion, as seen in (j) measured blood flow in the ischemic limbs, normalized to the contralateral non-ischemic limbs, 7 days after surgery and (k) representative laser Doppler perfusion images. (I) Systemic IVlg suppressed laser injury-induced choroidal angiogenesis volume in a dose-dependent manner. IVlg doses ranged from 0.017 to $2 \mathrm{~g} / \mathrm{kg}$, delivered twice (on the day of injury and 3 days later); $n=6-8$. (m) Local intravitreous injection of IVlg (40 $\mu \mathrm{g}$ in $1 \mu \mathrm{l})$ suppressed choroidal angiogenesis in wild-type mice; $n=12$. Results are means \pm s.e.m. ${ }^{*} P<0.05$ compared with PBS or IV PBS. 
To confirm the in vivo existence of IVIg-FcyRI engagement in the angiosuppressive process, we assessed the presence of IVlg in the injury sites of the different mouse models after its IV administration by multiple strategies. First, we assessed the extravascular levels of human IgG (corresponding to the injected IVlg of human origin) by enzyme-linked immunosorbent assay in the corneal, retinal and choroidal tissues, and verified that they greatly exceeded those of endogenous mouse $\operatorname{lgG} 2 \mathrm{c}$ (Figure 3a), the IgG isotype of $\mathrm{C} 57 \mathrm{BL} / 6 \mathrm{~J}$ mice that binds $\mathrm{mFc} / \mathrm{RI}$ with high affinity. ${ }^{24}$ Second, using immunostaining in the hind limb ischemia and xenograft colon carcinoma models, we visualized human $\mathrm{lgG}$ in the extra-fiber space of muscle and also in the tumor stroma after administering systemic IVIg (Figures $3 \mathrm{~b}$ and $\mathrm{c}$ ). Finally, using a pull-down assay, we determined that biotinylated IVIg injected IV into wild-type mice coprecipitated with $\mathrm{FcyRl}$ in their corneas after suture injury (Figure 3d). Collectively, these data suggest that, similarly to human IgG1, IVIg interacts with $\mathrm{Fc \gamma RI}$ in vivo and suppresses
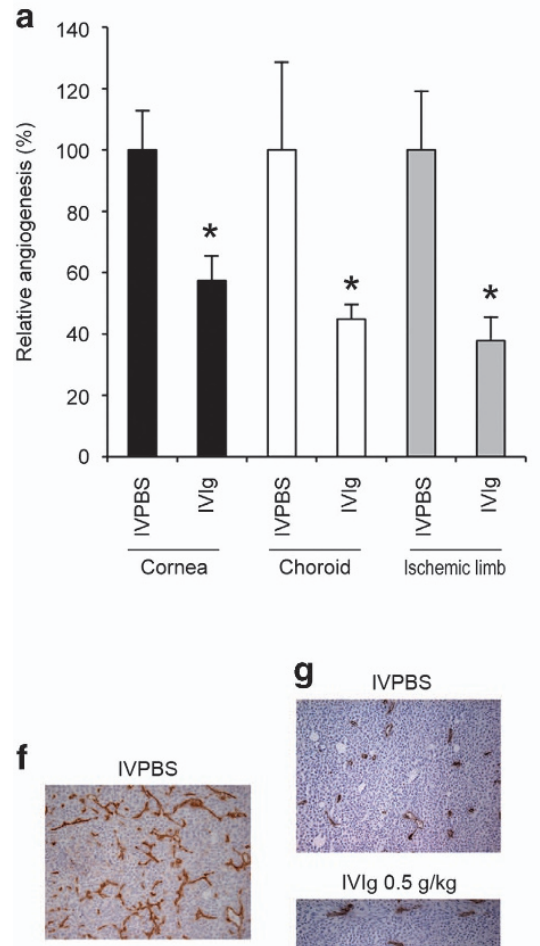

$\mathrm{IVIg}$
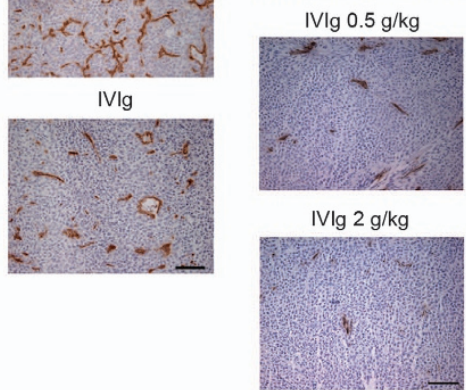

b

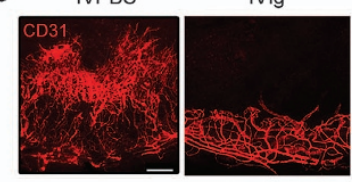

C
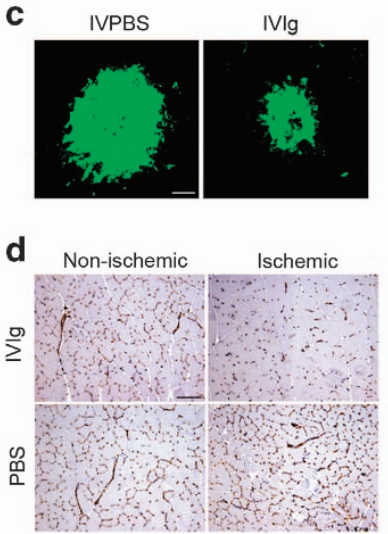

e

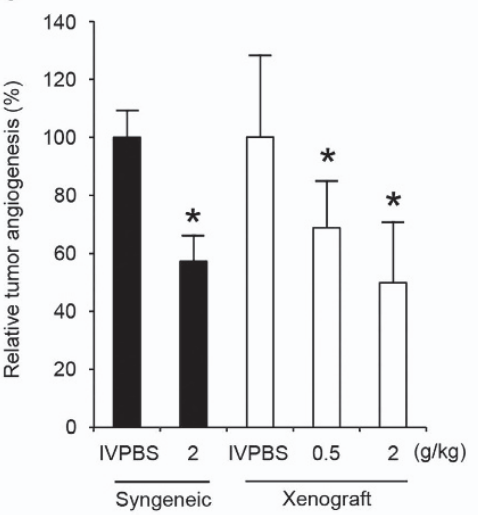

h

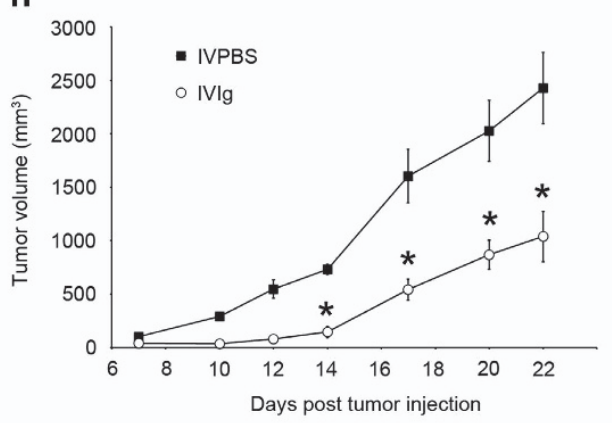

i

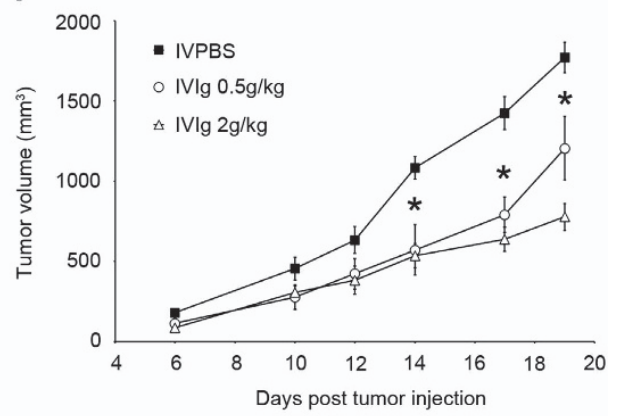

k
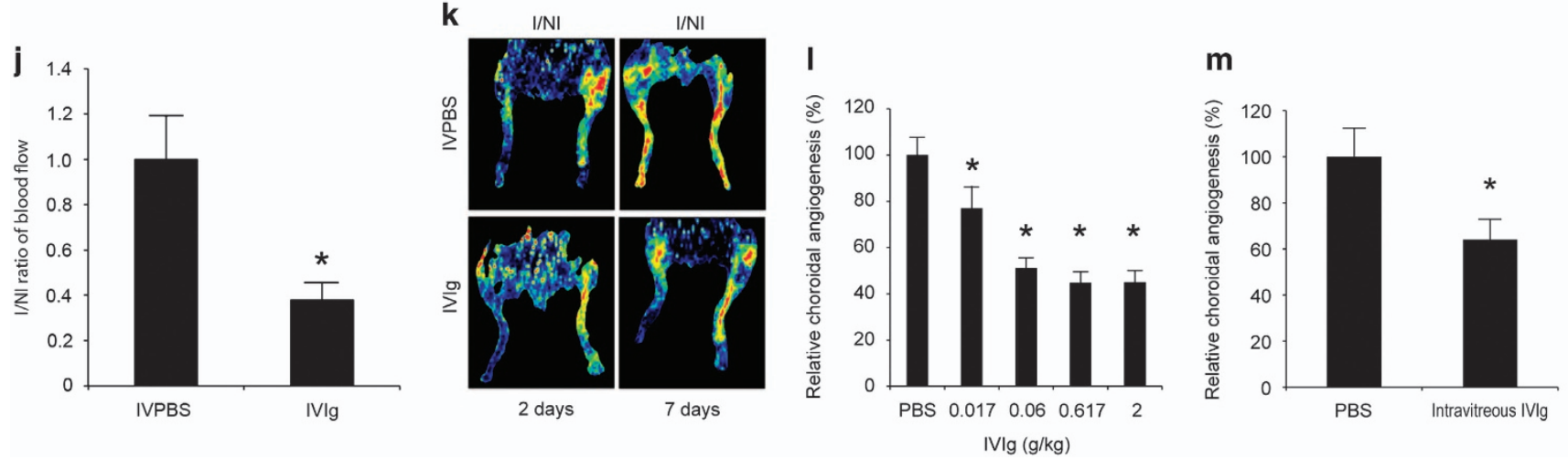
a

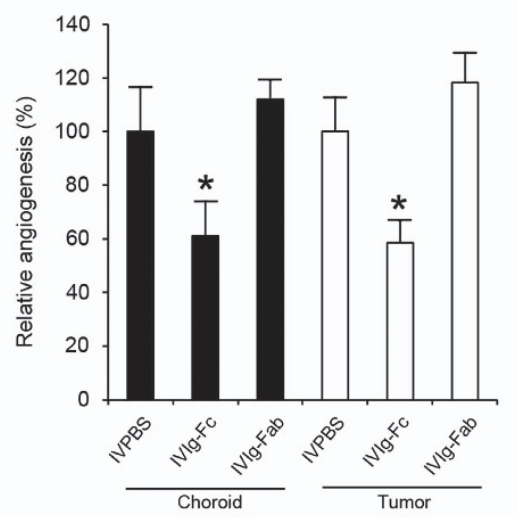

b

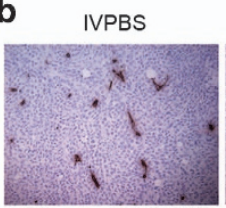

IVIg-FC
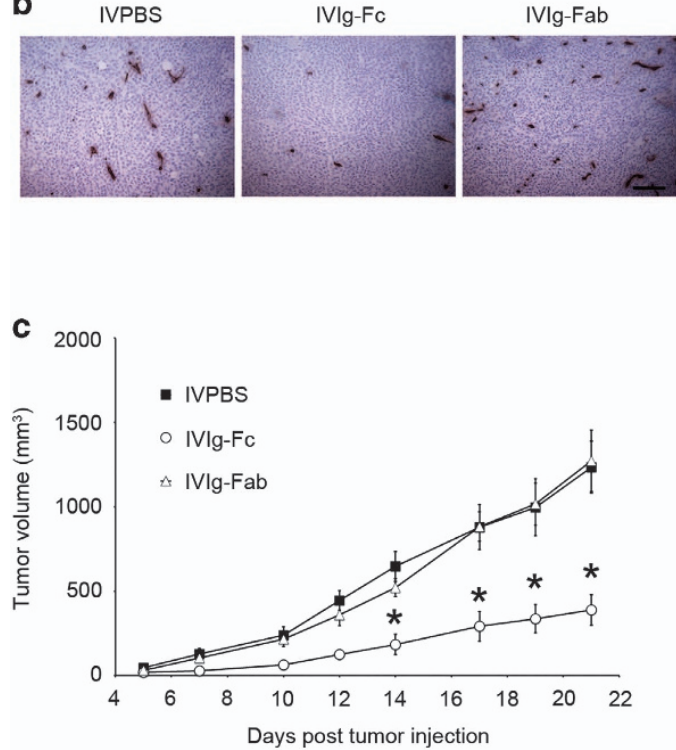

d

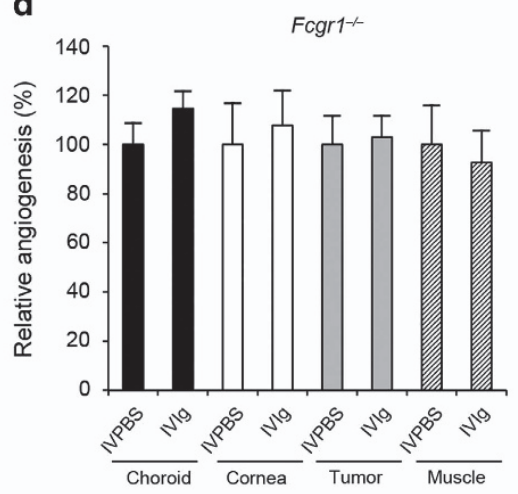

e

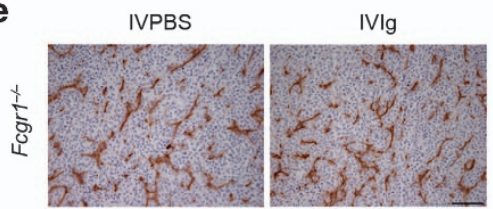

g

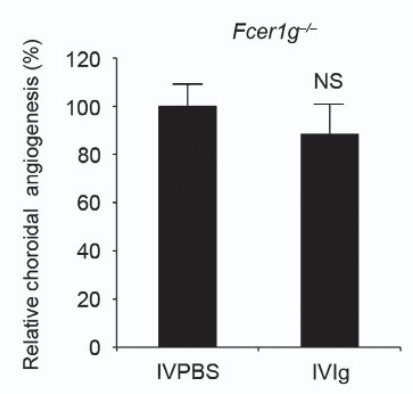

h

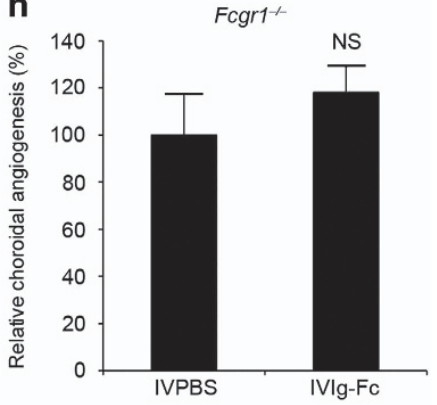

Figure 2. IVlg inhibited mouse angiogenesis via its Fc fragment and Fc $7 R I$ engagement. (a, b) The Fc fragment of IVlg (IVlg-Fc), but not the Fab fragment (IVlg-Fab), inhibited choroidal angiogenesis in wild-type mice and xenograft tumoral angiogenesis in nude mice, as seen in (a) quantification of choroidal angiogenesis volume $(n=4-8)$ and tumor CD31 immunolocalization $(n=7)$ compared with PBS group (IV PBS), and (b) representative histology images of tumor tissue (CD31+, brown). Scale bar, $100 \mu \mathrm{m}$. (c) IVlg-Fc, but not IVlg-Fab, suppressed xenograft tumor growth, as compared with PBS. (d) IVlg did not inhibit choroidal $(n=6-8)$, corneal $(n=8)$ syngeneic tumor $(n=7)$ or muscle $(n=8)$ angiogenesis in $\mathrm{Fcgr1}^{-}-$mice, which lack FcyRl. No significant difference between groups. (e), Representative histology images of syngeneic tumor tissue in $\mathrm{Fcgr1}^{-1-}$ mice (CD31+, brown) treated with either IVIg or IV PBS. Scale bar, $100 \mu \mathrm{m}$. (f) IVlg did not suppress tumor growth in $\mathrm{Fcgr1}^{-1-}$ mice, as compared with IV PBS. $n=7$. (g) IVIg did not inhibit choroidal angiogenesis in Fcer1g ${ }^{-/-}$mice, which lack functional signaling of activating FcyRs; $n=6$. (h) IVlg-Fc did not inhibit choroidal angiogenesis in Fcgr1 $1^{-1-}$ mice. $n=6$. Results are means \pm s.e.m. ${ }^{*} P<0.05$ compared with IV PBS.

angiogenesis in mice via this receptor. Igs bind not only to FcyRs but also to C1q, and some effects of IVIg have been attributed to complement activation. ${ }^{25}$ However, IVIg retained its antiangiogenic activity in $\mathrm{Clqa}^{-1-}$ mice (Supplementary Figure 4), suggesting that complement activation is not required for this function of IVlg.

Although human IgG1 binds both mouse and human $\mathrm{FcyRl}{ }^{26}$ mouse and human FcyRs have species-specific structural diversity and cellular expression patterns. ${ }^{27}$ Therefore, we sought to determine whether the angioinhibitory effects of IVIg in mice also could be observed in the setting of human FcyRs. We first studied the transgenic FcyR humanized mouse, which expresses the entire human FcyR family, under the control of their human regulatory elements, on a genetic background lacking all mouse FcyRs. ${ }^{28}$ Consistent with our observation, ${ }^{5}$ as well as those of others, ${ }^{29}$ that human IgG1 binds human FcyRl in vivo, and with the notion that IVlg mediates angioinhibition via FcyRI, IVIg reduced choroidal and corneal angiogenesis in FcyR humanized mice as efficiently as in wild-type mice (Figures $4 a$ and b). Further, concomitant administration of IVlg with a small interfering RNA targeting FCGRIA (the gene encoding human FcyRl) abrogated this angioinhibitory effect in FcyR humanized mice (Figure 4c). In this humanized model, IVIg induced phosphorylation of FcyRl, both in the corneas and in the white blood cells of mice (Figures $4 \mathrm{~d}$ and e), thereby strengthening the notion that IVIg induces signaling via this receptor.

We then examined renal or muscle biopsies of human patients obtained before and after treatment with IVlg for renal transplant rejection ${ }^{30}$ or inflammatory myopathies, ${ }^{31}$ respectively (Supplementary Table). Strikingly, biopsies of patients obtained after receiving IVIg displayed reduced blood vessel density in the kidneys or muscles; however, there was no reduction in blood vessel density in the kidneys of patients that underwent plasmapheresis as an alternative therapy to IVlg (Figures $4 \mathrm{f}-\mathrm{i}$ ). These data, derived from genetically diverse patient populations in different countries, are a confirmation that in humans clinical 
a

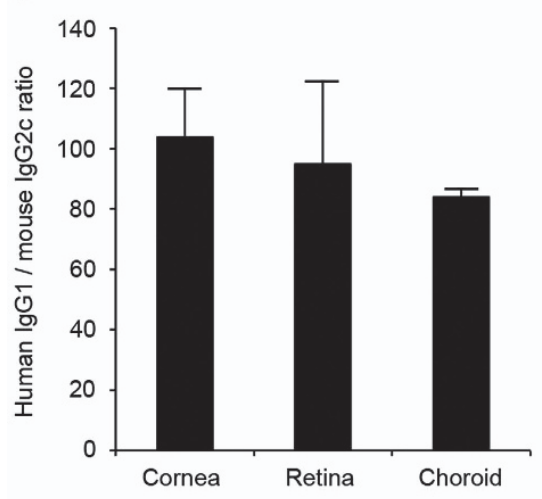

C
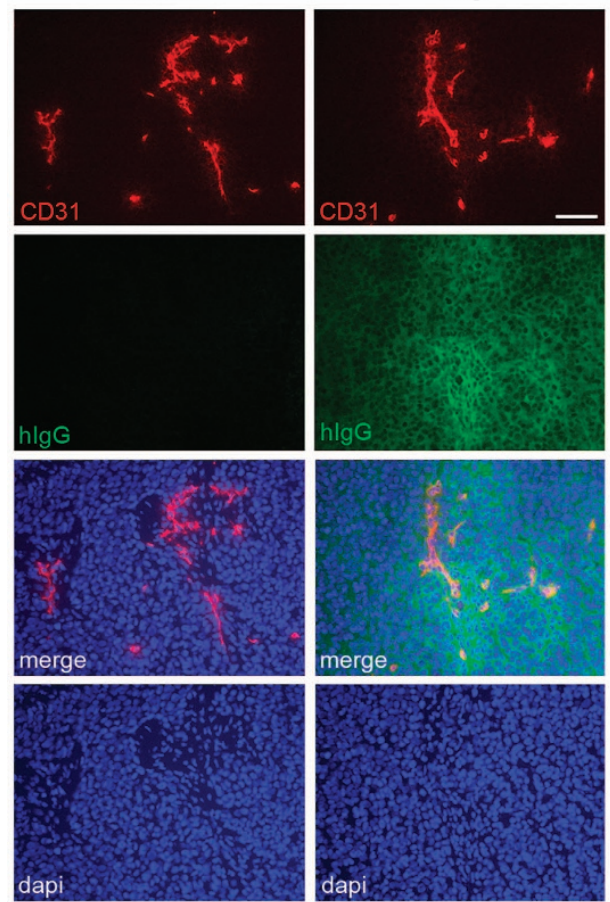

b
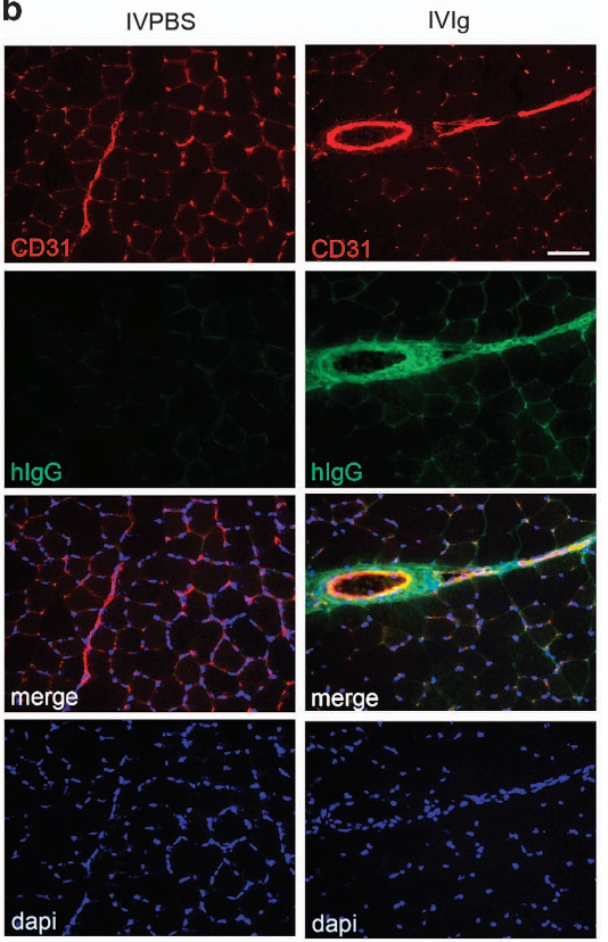

Figure 3. IVlg is present in tissue where angioinhibition occurs and binds mouse FcyRI (mFcyRI). (a) IVlg injected IV was present in corneal, retinal and choroidal tissues, and its levels exceeded those of endogenous mouse IgG2c, as assessed by human IgG1 enzyme-linked immunosorbent assay (ELISA) and mouse lgG2c ELISA. Mice were subjected to corneal suture placement or choroidal laser injury, and IVlg was injected in the same scheme used for in vivo angiogenesis experiments $(2 \mathrm{~g} / \mathrm{kg}$, on days 1 and 3 ). Tissue was harvested and processed for ELISA on day 3. (b) Immunostaining of muscle tissue in wild-type mice was positive for human IgG after systemic administration of IVlg. Scale bar, $100 \mu \mathrm{m}$. (c) Immunostaining of tumor tissue from colon carcinoma xenografts in nude mice was positive for human IgG after systemic administration of IVlg. Scale bar, $100 \mu \mathrm{m}$. (d) Pull-down assay revealed the presence of IVlg in corneal tissue following suture injury. After systemic administration, biotinylated IVIg was pulled down from the corneal tissue lysate and the eluted proteins were blotted for $\mathrm{mFc} \gamma \mathrm{RI}$.

doses of IVlg can modulate blood vessel density. Although these findings are consistent with our data on suppression of angiogenesis by IVIg via FcyRI in numerous mouse models, we cannot conclude that the reduced blood vessel density in patients treated with IVIg is mediated by FcyRl, as it is possible that other effects of IVlg might be responsible for this action in humans.

\section{DISCUSSION}

Here we present the discovery that IVIg suppresses blood vessel growth via Fc-FcyRI engagement. IVIg inhibited ocular, muscle and tumor angiogenesis, demonstrating a broad angioinhibitory effect on varying blood vessel types and in diverse tissue environments. Further, the human data demonstrating that IVIg therapy modulates angiogenesis when administered at a dose routinely used in the clinical setting indicates that IVIg-induced angioinhibition also occurs in humans. These data go hand-inhand with our recent findings that multiple therapeutic human monoclonal IgG1 antibodies, as a class, possess the same angioinhibitory effect via FcyRI. ${ }^{5}$

Treatment with IVIg has been reported to be anti-metastatic both in animal models ${ }^{32}$ and in humans. ${ }^{32,33}$ Our demonstration that IVIg concomitantly decreases blood vessel density and tumor growth suggests that angioinhibition might be an important 
a

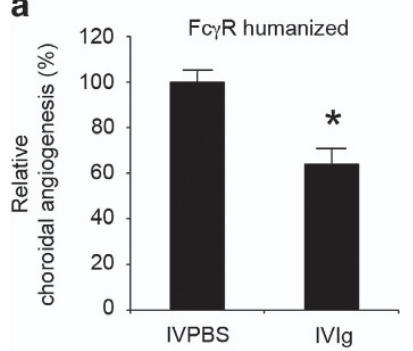

b
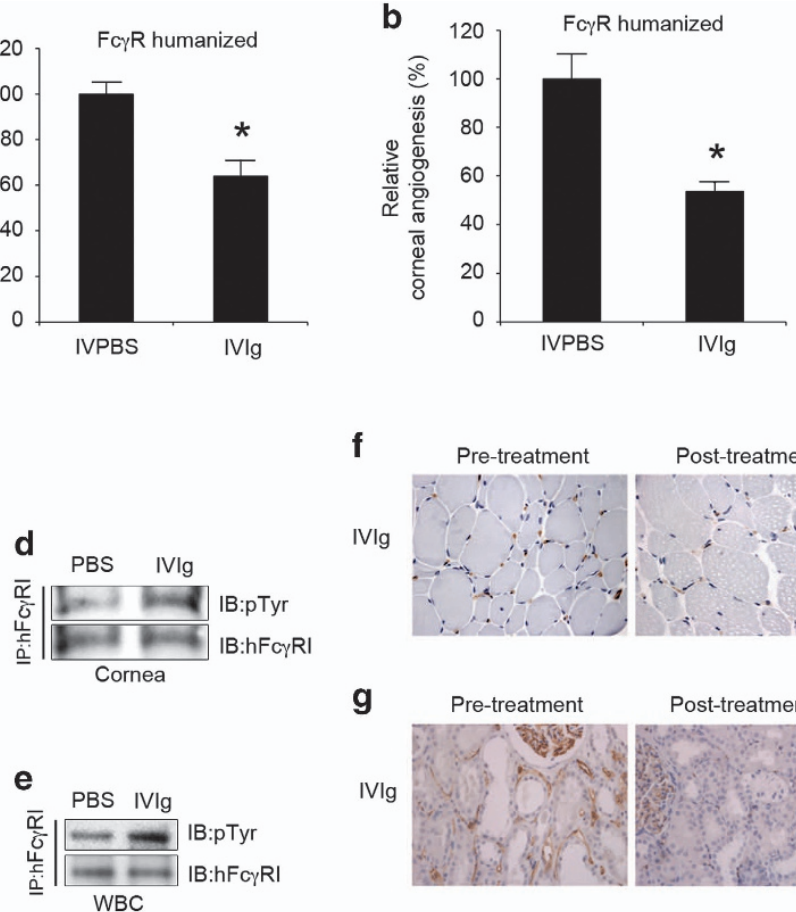

f

IVIg

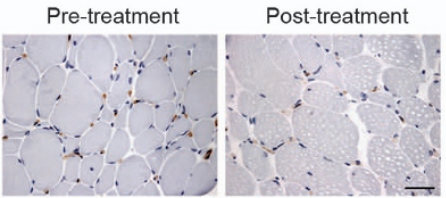

g

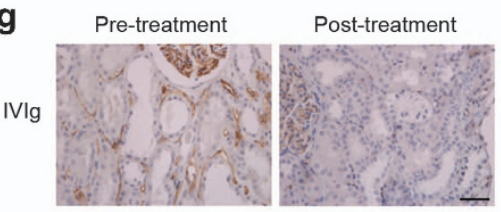

h

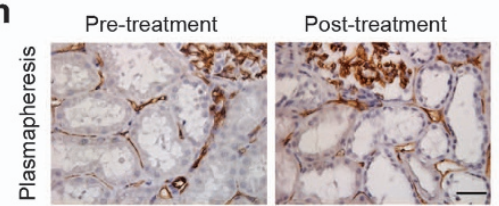

C

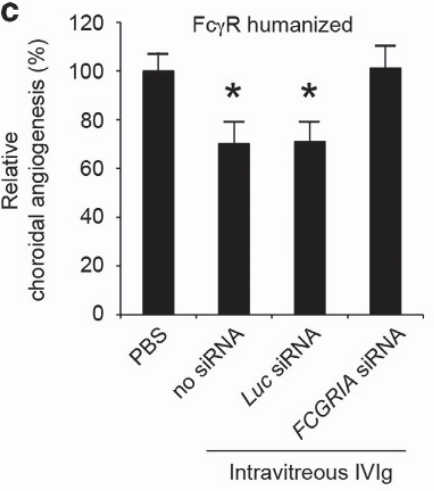

i

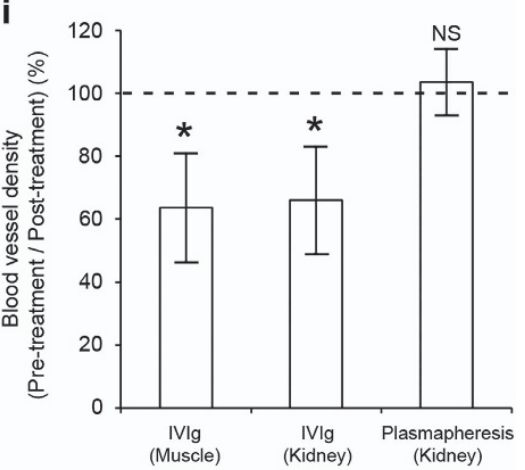

Figure 4. IVIg is angioinhibitory in FcyR humanized mice and in human patients. (a) IVlg inhibited choroidal angiogenesis in FcyR humanized mice, which express the human isoforms of FcyRs and lack the mouse isoforms of these receptors, as compared with IV PBS; $n=6$. (b) IVlg inhibited corneal angiogenesis in FcyR humanized mice; $n=6$. ${ }^{*} P<0.05$ compared with IV PBS (a, b). (c) Intravitreous IVIg did not inhibit choroidal angiogenesis in FcyR humanized mice when co-administered with an intravitreous small interfering RNA targeting FCGR1A, the human gene encoding Fc $\gamma \mathrm{Rl} ; n=12-14 .{ }^{*} P<0.05$ compared with PBS and FCGR1A small interfering RNA. (d, e) IVlg induced phosphorylation of FcyRl in humanized mice. Mice were subjected to corneal suture placement and treatment with IVlg or IV PBS, and (d) cornea or (e) white blood cell lysates were immunoprecipitated with anti-Fc $\gamma \mathrm{RI}$ antibodies and were immunoblotted with the indicated antibodies. (f-h) Representative immunohistochemistry images of biopsies of (f) muscle or (g) kidney from patients treated with IVlg, or (h) kidney from patients treated with plasmapheresis, showing tissue density of blood vessels (CD31+, brown) is reduced after treatment with IVlg, but not after plasmapheresis. Scale bars, $50 \mu \mathrm{m}$. (i) Mean changes in blood vessel density (post- versus pre-treatment). Error bars indicate $95 \%$ confidence intervals. ${ }^{*} P=0.002\left(n=8\right.$, muscle), ${ }^{*} P=0.006(n=10$, kidney, IVlg-treated patients), not significant (NS; $n=3$, kidney, plasmapheresis-treated patients) comparing post- versus pre-treatment, two-tailed paired Student $t$-test.

determinant in its effect on decreasing tumor progression and invasion. We recently showed that hlgG1-mediated angioinhibition is associated with decreased macrophage migration and infiltration of angiogenic sites via FcyRl engagement. ${ }^{5}$ We have demonstrated a similar inhibitory effect on macrophage migration by IVlg in ischemia muscle. Because infiltration of tumors by tumor-associated macrophages is associated with increased cancer vascular grade and progression, ${ }^{34}$ such a mechanism of action of IVlg might contribute to the decrease in tumor volume we observed.

The neovascular form of AMD, the leading disease responsible for blindness in the elderly in industrialized countries, ${ }^{35}$ is caused by choroidal angiogenesis in the macula, the central region of the retina responsible for high-acuity vision. Currently, the standard treatment for this disease is monthly intraocular injections of antiVEGFA agents such as bevacizumab, ranibizumab or aflibercept. These drugs are currently responsible for roughly one-sixth of the Medicare Part B fee-for-service program expenses. ${ }^{36-38}$ In this work we demonstrate that, in the mouse model of neovascular AMD we used, $40 \mu \mathrm{g}$ of intravitreous IVlg inhibited choroidal angiogenesis as effectively as anti-VEGFA antibodies do. ${ }^{5}$ Translated to the human eye vitreous volume, this would correspond to an approximate dose of $22 \mathrm{mg}$ (which is contained in $220 \mu \mathrm{l}$ of the commercially available IVlg preparations at $100 \mathrm{mg} / \mathrm{ml}$ ), making it substantially more affordable than current US food and drug administration-approved therapies. Further, intravitreous IVIg has been previously shown to not induce retinal inflammation in a rabbit model, in doses far higher than the ones used in our studies, ${ }^{39}$ suggesting that it is likely to be safe for use in human eye diseases.

Our data also raise the possibility that IVlg might induce undesirable effects on the blood vasculature in other diseases and should prompt monitoring for such effects. The potential functional consequences of such vascular disturbances remain to be determined. Among the innumerable diseases for which IVlg is used in an 'off-label' manner is Alzheimer's disease. Although it has been postulated that IVIg clears $\beta$-amyloid deposits, ${ }^{40}$ a phase 3 clinical trial recently reported that IVlg did not provide benefit in Alzheimer's disease. Whether suppression of angiogenesis by IVlg via FcyRl might have contributed to this absence of therapeutic benefit warrants further study. Likewise, it would be worthwhile exploring whether possibly detrimental FcyRl-mediated angioinhibition had a 
role in the failures of several monoclonal antibody therapies in clinical trials in Alzheimer's disease and diabetes.

Our studies put forward a novel role for IVIg as an angiosuppressive drug, potentially applicable in multiple human diseases. IVlg may be ripe for rapid repurposing as a systemic angioinhibitory agent and in the near future as an intraocular inexpensive therapy for multiple neovascular blinding diseases, such as AMD, proliferative diabetic retinopathy or retinopathy of prematurity. We also propose that, in view of our data, systemic use of IVlg should be accompanied by monitoring of adverse effects in blood vessels, particularly in patients at risk for vascular diseases.

\section{ACKNOWLEDGEMENTS}

We thank TS Khurana, S Bondada, K Ambati, AM Rao and GS Rao for discussions: L Toll, GR Pattison R King, L Xu, M McConnell, C Payne, D Robertson, G Botzet, A Uiettenbogaard, E Lindroos and the Institute of Genetics and Biophysics animal house and integrated microscopy facilities for technical assistance. JA was supported by US National Institutes of Health (NIH) grants DP1GM114862, R01EY018350, R01EY018836, R01EY020672, R01EY022238 and R01EY024068, Doris Duke Distinguished Clinical Scientist Award, Burroughs Wellcome Fund Clinical Scientist Award in Translational Research, Ellison Medical Foundation Senior Scholar in Aging Award, Foundation Fighting Blindness Individual Investigator Research Award, Harrington Discovery Institute Scholar-Innovator Award, Carl Marshall Reeves Foundation, John Templeton Foundation, Dr E Vernon Smith and Eloise C Smith Macular Degeneration Endowed Chair, and Research to Prevent Blindness departmental unrestricted grant; SDeF by AIRC (Associazione Italiana Ricerca sul Cancro) grant IG11420 and Italian Ministry for Scientific Research, project PON01_01434; BJF and SB by NIH T32HL091812 and UL1RR033173; YH by Alcon Research Award; AB-C by the Programme for Advanced Medical Education (sponsored by Fundação Calouste Gulbenkian, Fundação Champalimaud, Ministério da Saúde and Fundação para a Ciência e Tecnologia, Portugal) and Bayer Global Ophthalmology Research Award; YH by Alcon Japan Research award; NK by Beckman Initiative for Macular Research and NIH K99/R00EY024336; CBW by International Retinal Research Foundation; BDG by American Heart Association and International Retinal Research Foundation; BKA by NIH R01EY017182 and R01EY017950, VA Merit Award and Department of Defense; and OV by Ministry of Health, Czech Republic-conceptual development of research organization (Institute for Clinical and Experimental Medicine-IKEM, IN 00023001).

\section{DISCLAIMER}

The content is solely the responsibility of the authors and does not necessarily represent the official views of the NIH.

\section{AUTHOR CONTRIBUTIONS}

RY, VC, TM, LT, YK, VT, SB, YH, NK, SL, TY, BJF, CBW, IA, AG, AB, BKA, BDG, AB-C and SDeF performed experiments. SBH, IEL, OV, JHWL and JSV provided animals, tissues or reagents. JA conceived and directed the project, and with assistance from $A B-C$, SDeF and BKA, wrote the paper. SDeF directed the execution of the hind limb ischemia and tumor experiments and histological analysis of human tissues. All authors had the opportunity to discuss the results and comment on the manuscript.

\section{COMPETING INTERESTS}

JA is a co-founder of iVeena Holdings, iVeena Pharmaceuticals, iVeena Delivery Systems and Inflammasome Therapeutics, and has received honoraria from Allergan and research funding from Olix Pharmaceuticals unrelated to this work. JA and SDeF are named as inventors on patent applications filed by the University of Kentucky relating to the technology described in this work.

\section{REFERENCES}

1 Gelfand EW. Intravenous immune globulin in autoimmune and inflammatory diseases. N Engl J Med 2012; 367: 2015-2025.

2 Viard I, Wehrli P, Bullani R, Schneider P, Holler N, Salomon D et al. Inhibition of toxic epidermal necrolysis by blockade of CD95 with human intravenous immunoglobulin. Science 1998; 282: 490-493.
3 Jolles S, Sewell WA, Misbah SA. Clinical uses of intravenous immunoglobulin. Clin Exp Immunol 2005; 142: 1-11.

4 Nimmerjahn F, Ravetch JV. Anti-inflammatory actions of intravenous immunoglobulin. Annu Rev Immunol 2008; 26: 513-533.

5 Bogdanovich S, Kim Y, Mizutani T, Yasuma R, Tudisco L, Cicatiello V et al. Human IgG1 antibodies suppress angiogenesis in a target-independent manner. Signal Transduction Target Ther 2016 (in press).

6 Nimmerjahn F, Ravetch JV. Divergent Immunoglobulin G subclass activity through selective Fc receptor binding. Science 2005; 310: 1510-1512.

7 Ravetch JV, Kinet JP. Fc receptors. Annu Rev Immunol 1991; 9: 457-492.

8 Unkeless JC, Eisen HN. Binding of monomeric immunoglobulins to Fc receptors of mouse macrophages. J Exp Med 1975; 142: 1520-1533.

9 Hirano Y, Yasuma T, Mizutani T, Fowler BJ, Tarallo V, Yasuma R et al. IL-18 is not therapeutic for neovascular age-related macular degeneration. Nat Med 2014; 20 : 1372-1375.

10 Albuquerque RJ, Hayashi T, Cho WG, Kleinman ME, Dridi S, Takeda A et al. Alternatively spliced vascular endothelial growth factor receptor-2 is an essential endogenous inhibitor of lymphatic vessel growth. Nat Med 2009; 15: 1023-1030.

11 Cho WG, Albuquerque RJ, Kleinman ME, Tarallo V, Greco A, Nozaki M et al. Small interfering RNA-induced TLR3 activation inhibits blood and lymphatic vessel growth. Proc Natl Acad Sci USA 2009; 106: 7137-7142.

12 Takeda A, Baffi JZ, Kleinman ME, Cho WG, Nozaki M, Yamada K et al. CCR3 is a target for age-related macular degeneration diagnosis and therapy. Nature 2009; 460: $225-230$

13 Couffinhal T, Silver M, Zheng LP, Kearney M, Witzenbichler B, Isner JM. Mouse model of angiogenesis. Am J Pathol 1998; 152: 1667-1679.

14 Kleinman ME, Yamada K, Takeda A, Chandrasekaran V, Nozaki M, Baffi JZ et al. Sequence- and target-independent angiogenesis suppression by siRNA via TLR3. Nature 2008; 452: 591-597.

15 Fowler BJ, Gelfand BD, Kim Y, Kerur N, Tarallo V, Hirano Y et al. Nucleoside reverse transcriptase inhibitors possess intrinsic anti-inflammatory activity. Science 2014; 346: 1000-1003.

16 Mizutani T, Fowler BJ, Kim Y, Yasuma R, Krueger LA, Gelfand BD et al. Nucleoside reverse transcriptase inhibitors suppress laser-induced choroidal neovascularization in mice. Invest Ophthalmol Vis Sci 2015; 56: 7122-7129.

17 Liotta LA, Kleinerman J, Catanzaro P, Rynbrandt D. Degradation of basement membrane by murine tumor cells. J Natl Cancer Inst 1977; 58: 1427-1431.

18 Brattain MG, Fine WD, Khaled FM, Thompson J, Brattain DE. Heterogeneity of malignant cells from a human colonic carcinoma. Cancer Res 1981; 41: 1751-1756.

19 Hanahan D, Weinberg RA. The hallmarks of cancer. Cell 2000; 100: 57-70.

20 Kim KJ, Li B, Winer J, Armanini M, Gillett N, Phillips HS et al. Inhibition of vascular endothelial growth factor-induced angiogenesis suppresses tumour growth in vivo. Nature 1993; 362: 841-844.

21 Weis SM, Cheresh DA. Tumor angiogenesis: molecular pathways and therapeutic targets. Nat Med 2011; 17: 1359-1370.

22 Siragam V, Crow AR, Brinc D, Song S, Freedman J, Lazarus AH. Intravenous immunoglobulin ameliorates ITP via activating Fcy receptors on dendritic cells. Nat Med 2006; 12: 688-692.

23 Samuelsson A, Towers TL, Ravetch JV. Anti-inflammatory activity of IVIG mediated through the inhibitory Fc receptor. Science 2001; 291: 484-486.

24 Zhang Z, Goldschmidt T, Salter H. Possible allelic structure of $\lg G 2$ a and $\operatorname{lgG} 2 \mathrm{C}$ in mice. Mol Immunol 2012; 50: 169-171.

25 Lutz HU, Späth PJ. Anti-inflammatory effect of intravenous immunoglobulin mediated through modulation of complement activation. Clin Rev Allergy Immunol 2005; 29: 207-212.

26 Overdijk MB, Verploegen S, Ortiz Buijsse A, Vink T, Leusen JH, Bleeker WK et al. Crosstalk between human IgG isotypes and murine effector cells. J Immunol 2012; 189: 3430-3438.

27 Bruhns P. Properties of mouse and human IgG receptors and their contribution to disease models. Blood 2012; 119: 5640-5649.

28 Smith P, DiLillo DJ, Bournazos S, Li F, Ravetch JV. Mouse model recapitulating human Fcy receptor structural and functional diversity. Proc Natl Acad Sci USA 2012; 109: 6181-6186.

29 Guilliams M, Bruhns P, Saeys Y, Hammad H, Lambrecht BN. The function of FcY receptors in dendritic cells and macrophages. Nat Rev Immunol 2014; 14: 94-108.

30 Slatinska J, Honsova E, Burgelova M, Slavcev A, Viklicky O. Plasmapheresis and intravenous immunoglobulin in early antibody-mediated rejection of the renal allograft: a single-center experience. Ther Apher Dial 2009; 13: 108-112.

31 Barbasso Helmers S, Dastmalchi M, Alexanderson H, Nennesmo I, Esbjornsson M, Lindvall B et al. Limited effects of high-dose intravenous immunoglobulin (IVIG) treatment on molecular expression in muscle tissue of patients with inflammatory myopathies. Ann Rheum Dis 2007; 66: 1276-1283.

32 Merimsky O, Meller I, Inbar M, Bar-Yehuda S, Shoenfeld Y, Fishman P. A possible role for IVIg in the treatment of soft tissue sarcoma: a clinical case and an experimental model. Int J Oncol 2002; 20: 839-843. 
33 Shoenfeld Y, Levy Y, Fishman P. Shrinkage of melanoma metastases following high dose intravenous immunoglobulin treatment. Isr Med Assoc J 2001; 3: 698-699.

34 Leek RD, Lewis CE, Whitehouse R, Greenall M, Clarke J, Harris AL. Association of macrophage infiltration with angiogenesis and prognosis in invasive breast carcinoma. Cancer Res 1996; 56: 4625-4629.

35 Ambati J, Atkinson JP, Gelfand BD. Immunology of age-related macular degeneration. Nat Rev Immunol 2013; 13: 438-451.

36 Hutton D, Newman-Casey PA, Tavag M, Zacks D, Stein J. Switching to less expensive blindness drug could save medicare part B $\$ 18$ billion over a ten-year period. Health Aff (Millwood) 2014; 33: 931-939.

37 Levinson DR. Executive Summary: Medicare payments for drugs used to treat wet age-related macular degeneration. In: Department of Health and Human Services USA (ed), 2012.

38 Blum J. Hearing on Sustaining the Medicare Program through Lower Costs. In: Department of Health and Human Services USA (ed), 2011.
39 Han DP. Intravitreal human immune globulin in a rabbit model of Staphylococcus aureus toxin-mediated endophthalmitis: a potential adjunct in the treatment of endophthalmitis. Trans Am Ophthalmol Soc 2004; 102: 305-320.

40 Sudduth TL, Greenstein A, Wilcock DM. Intracranial injection of Gammagard, a human IVIg, modulates the inflammatory response of the brain and lowers $A \beta$ in APP/PS1 mice along a different time course than anti-A $\beta$ antibodies. J Neurosci 2013; 33: 9684-9692.

This work is licensed under a Creative Commons Attribution 4.0 International License. The images or other third party material in this article are included in the article's Creative Commons license, unless indicated otherwise in the credit line; if the material is not included under the Creative Commons license, users will need to obtain permission from the license holder to reproduce the material. To view a copy of this license, visit http://creativecommons.org/licenses/by/4.0/

Supplementary Information accompanies the paper on the Signal Transduction and Targeted Therapy website (http://www.nature.com/sigtrans) 